\title{
A EDUCAÇÃO E SEUS CONDICIONANTES FRENTE AO ÊXODO RURAL
}

Denise Sikora $^{1}$

UNICENTRO

\section{RESUMO}

Neste trabalho desenvolve-se uma análise sobre o êxodo rural e o papel que a educação tem para conter esse fato. Objetivou-se compreender a Educação do Campo e seus condicionantes, ou alterações em relação à sua função social, política e cultural. Inicialmente é analisado o êxodo rural e suas implicações na Educação do Campo no século XX. Em seguida, aborda se há entre as políticas públicas atuais para a Educação do Campo uma relação com o êxodo rural. Finalmente identifica a função social da Educação do Campo em relação ao êxodo rural. Resultante de uma pesquisa bibliográfica, a reflexão empreendida indicou que vivemos em uma sociedade do conhecimento baseada pela tecnologia que desenvolve e estimula a competição entre as pessoas. Nessa perspectiva, a educação desempenha um papel relevante na construção da sociedade embalada pela industrialização que retirou muitas pessoas do campo, no entanto, ela não tem por função a contenção do êxodo.

Palavras-chave: Êxodo Rural; Educação do Campo; Educação e Emancipação.

\section{THE EDUCACION AND ITS CONDITIONS AHEAD TO RURAL EXODUS}

\begin{abstract}
This paper developed an analysis of the rural flight and the role that education has to contain it. The study aimed at understanding the Rural Education and its conditions, or changes in relation to its social, political and cultural function. Initially, the rural exodus and its implications for rural education in the twentieth century were analyzed. Then, it focuses if there is a relationship between the current public policies for the Rural Education and the rural flight. Finally this work identifies the social function of Rural Education in relation to the rural exodus. A reflection resulting from a literature review indicated that we live in a knowledge society based on technology that develops and encourages competition between people. From this perspective, education plays an important role in building a society stimulated by industrialization that has taken many people out the field, however, it does not have the power to contain the exodus.
\end{abstract}

Keywords: Rural Exodus, Rural Education, Education.

\section{Introdução}

Historicamente, pode-se observar que a Educação do Campo $^{2}$ no Brasil esteve relegada a um segundo plano, especialmente se for considerada em comparação à educação no meio urbano, isso se dá especialmente pela dicotomia campo/cidade. A partir dessa constatação, considera-se que uma análise aprofundada dos processos educativos deve ser realizada em contraposição aos outros aspectos históricos que caracterizam o Campo no Brasil no século XX, tais como: o $\hat{E} x o d o$ Rural $^{3}$, o analfabetismo, a modernização agrícola e, recentemente, a pressão por parte dos movimentos sociais. 
Considera-se que um dos principais aspectos relativos ao tema a partir do século XX seja o Éxodo Rural. Do confronto entre esse movimento e as práticas educativas surge como objetivo desse artigo investigar as possíveis relações entre os processos educativos para a Educação do Campo com o Exxodo Rural no decorrer do século XX e como desdobramento compreender a Educação do Campo e seus condicionantes, ou alterações em relação à sua função social, política e cultural.

Os estudos sobre os processos educativos do Campo apontam várias lacunas no que diz respeito ao seu desenvolvimento. A tendência é que seja considerada como melhor a educação ofertada na cidade, pois a valorização pelo espaço rural ocorreu, principalmente, quando o processo de desenvolvimento nacional se intensificou. Mesmo assim, muitos moradores deste espaço deixaram o meio, já conhecido, para buscar novas atividades nas cidades.

Inicialmente, a análise aqui empreendida tinha como problema central explicitado a investigação da relação entre o processo educativo e a ocorrência do Êxodo Rural. No decorrer da pesquisa outros problemas surgiram tais como: quais os condicionantes históricos da Educação do Campo e do Exxodo Rural no século XX? E ainda, qual a função social da Educação do Campo na atualidade?

Considerando isso, o presente trabalho utiliza-se de fontes bibliográficas para demonstrar o papel da educação em relação ao êxodo no século passado. Esta pesquisa é realizada através de uma abordagem qualitativa que, segundo Godoy (1995), não enumera o objeto de estudo, nem analisa os dados estatisticamente, mas busca obter dados descritivos sobre pessoas, lugares e processos interativos pelo contato direto do pesquisador com o seu estudo.

Busca-se compreender os processos educativos a partir dos condicionantes históricos, políticos, econômicos e sociais do período, articulados ao movimento característico do modo de produção capitalista. No mesmo sentido, o Êxodo Rural deve ser compreendido ligado às demandas do modo de produção capitalista a partir da modernização da agricultura.

Inicialmente é apresentado um histórico da Educação do Campo partindo da década de 1930 até 1990, identificado como um momento em que o movimento migratório da população do campo para o meio urbano foi intensificado, tal apresentação objetiva caracterizar a educação brasileira ao longo do século XX em sua relação com o $\hat{E} x o d o$ Rural, articulados com o processo de modernização do campo característico do modo de produção capitalista. Nesse tópico, destaca-se a influência do ruralismo pedagógico na elaboração de projetos que visava uma instrução para as pessoas que moravam no campo continuar produzindo sem abandonar suas terras para buscar novas oportunidades de trabalho nas cidades.

Num segundo momento, apresenta-se a possível função da escola frente ao processo do Exxodo Rural. Verifica-se que a Educação do Campo pode ser considerada diferente da educação da cidade, seu foco pode ser outro, suas metodologias e recursos também, entretanto, entende-se que a educação possui um papel fundamental no processo de formação do indivíduo. Nesse sentido, ela necessita apresentar um caráter emancipatório que proporcione o conhecimento para as pessoas terem a liberdade de escolher o que deve ser bom para elas sem que ninguém dite os passos de como seguir.

Nota-se que a educação recebe uma conotação diferente em vários momentos da história. Ora ela é responsabilizada pela pouca produção dos agricultores e pelo processo do Éxodo Rural, ora como fundamental para ajudar a desenvolver integralmente a comunidade rural nas concepções sociais, econômicas, políticas e culturais de todos os envolvidos no processo educativo. 


\section{Condicionantes históricos da educação do campo em relação ao êxodo rural}

As várias discussões a respeito da temática Educação do Campo ou mesmo, sobre o próprio Campo, não são exclusivamente do século XXI, assim como as ações de resistência em contraposição à exploração e às grandes concentrações fundiárias, bem como as lutas pelo trabalho, pela conquista da terra e de condições dignas de sobrevivência, enfim, são questões que se apresentaram no Brasil ao longo do século XX, especialmente, articuladas a vários outros debates.

Sobre a problemática da Educação do Campo no Brasil e suas implicações na prática escolar, suas relações com os movimentos sociais, com o desenvolvimento econômico e social das comunidades, enfim, sobre as possíveis interferências que as práticas acarretam Bezerra Neto (2003) argumenta que ela se intensificou ainda mais quando os Movimentos Sociais ${ }^{4}$, incluindo o Movimento dos Trabalhadores Sem Terra (MST), que passaram a defender um novo paradigma social com a reforma agrária e a educação como elemento que poderia auxiliar na diminuição da exploração do trabalho e na "fixação" do homem no campo. Este autor vai afirmar que existe uma lacuna na historiografia da educação brasileira no que se refere a entender o proposto pelos Ruralistas $^{5}$, na metade do séc. XX, em contraposição ao que é defendido pelos Movimentos.

Deste modo, ressalta-se que a história da Educação do Campo perpassa pelo menos duas perspectivas, que seriam: as dos Ruralistas de um lado e as dos Movimentos Sociais do Campo de outro. Nesse contexto, compreende-se que a Educação serviria de interesse para quem produziria muito e ao mesmo tempo, um pouco mais tímida, para os Movimentos que buscavam por meio da sua organização e estruturação o reconhecimento e valorização do trabalhador do campo. Diante dessas perspectivas, pela análise histórica, busca caracterizar a Educação do Campo ou Educação Rural ${ }^{6}$ brasileira ao longo do século XX em sua relação com o Êxodo Rural, articulados com o processo de modernização do campo característico do modo de produção capitalista.

A respeito da educação, em meados do século XX, para o meio rural, Bezerra Neto (2003, p.15), afirma que as propostas para educação elaboradas por Sud Menucci, Carneiro Leão e Alberto Torres, na metade do século passado, propôs a formação de uma pedagogia que "fixasse" o trabalhador no meio rural. Esse sistema ficou conhecido como "ruralismo pedagógico". Vale aqui caracterizar que a proposta dos Ruralistas, apresentava cunho capitalista e nacionalista.

Pode-se considerar que o cenário brasileiro da educação no período foi resultado de influência de como estavam as condições políticas e econômicas do país. No início da década de 1930, a economia brasileira sentia os efeitos da crise cíclica do capitalismo, conforme destaca Bezerra Neto (2003), passava por dificuldades financeiras com o enfraquecimento da oligarquia cafeeira. Nesse sentido, até a revolução de 1930 a concepção dualista da educação era forte, para os pobres o pouco e para os ricos o ensino propedêutico. Com Gustavo Capanema, ministro da educação e saúde da época, a educação assumiu um papel importante na implementação da chamada "missão pedagógica", onde se disseminou a cultura local como tentativa de intensificar e massificar a educação oferecida às classes trabalhadoras. Conforme Bareiro (2007) foi a partir de 1930 que começou a se pensar num ensino diferenciado para a Educação no meio rural.

Nesse período quando referia-se ao homem do campo, expressava-se uma forma de tratamento, carregado também de juízo de valor: uma vida 
pacata e sem perspectiva de desenvolvimento; suas atitudes demonstram o conformismo com a situação em que vivem; jeito simples e sem dinamismo ou malícia; sotaque carregado que por muitas vezes usamos justamente para denotar a falta de instrução durante uma conversa ou brincadeira; a cordialidade e simplicidade dessas pessoas que dispendem pouco interesse, e o pensamento vigente de que o pouco que se faça por eles já está de bom tamanho. (BAREIRO, 2007, p.14-15)

Essa ridicularização do homem que mora no campo intensificou o movimento populacional rumo às cidades, pois atraiam público para trabalhar nas indústrias. Por outro lado, a educação no meio urbano não valorizava essa diferenciação. Era mais um ensino comum, básico que buscava preparar o aluno para uma vocação profissional que poderia ser tanto no meio urbano quanto no meio rural.

Em 1948 foi implementado no Brasil a extensão rural ou assistência técnica que ajudava na formação de professores rurais. Sua primeira fase foi denominada de "humanismo assistencialista" durando até a década de 1960. Comumente as equipes eram formadas por profissionais da área de economia domésticas e agrícola. Já a segunda fase que se refere ao período de 1960 a 1980, ficou intitulada "difusionismo produtivista". Foi nessa fase que aumentou em muito o crédito agrícola. Assim, houve a tentativa de colocar o homem do campo na dinâmica do mercado, uma vez que se desejava cada vez mais o aumento de produtividade e, para tanto, era necessário uma mudança na forma de pensar dessas pessoas.

Nota-se uma diferença em relação à escola desde o ruralismo pedagógico e a época da modernização. Naquela época a escola era vista como algo para manter o homem no campo, e posteriormente passou a ser disseminadora de formas e técnicas para produzir. Segundo Aplle, (1979, p. 97) não é fortuito o conhecimento que se introduziu nas escolas no passado e que hoje se introduz. É selecionado e organizado em torno de conjuntos de princípios e valores que provêm de alguma parte, que representam determinadas visões de normalidade e desvio, de bom e mau, e do modo como "agem as boas pessoas". Nessa perspectiva, há a definição de conteúdos padrão para as escolas.

De acordo com o mesmo autor, as escolas não controlam apenas pessoas, elas também ajudam a controlar significados, ao preservarem e distribuírem o que é considerado como o "conhecimento legítimo" - o conhecimento que "todos devemos ter" as escolas conferem legitimação cultural ao conhecimento de grupos específicos (APLLE, 1979, p. 98). No caso da história da educação brasileira, o conhecimento legítimo era o dos centros urbanos. Outro ponto a ser ressaltado nesse processo de legitimação refere-se à preocupação com a precariedade dos estabelecimentos, a falta de material didático e também a formação dos professores que atuavam no meio rural. Apesar do discurso recorrente de melhorias nas estruturas das instituições, verifica-se que as escolas rurais espalhadas pelo Brasil, historicamente, não apresentavam condições mínimas exigidas para estudar, o que impulsionava ainda mais a busca por "melhores" escolas localizadas nos centros urbanos.

Com a era Vargas, observa-se a instalação de um Estado centralizador, autoritário, empreendedor que buscou promover a integração nacional, bem como a sua modernização. Nesse contexto, pode-se dizer que emergiu a ideologia da "fixação" do homem no campo (BEZERRA NETO, 2003). É com ela que o currículo tenta atender as necessidades desse meio, com informações que pudessem ser usadas no seu cotidiano como, por exemplo, a pecuária e a agricultura. No entanto, a contradição ideológica já estava inscrita na própria formação dos professores, uma vez não se criou escolas normais rurais para atender essas necessidades, mas sim um curso de ruralismo anexo às escolas normais já existentes. Esses 
cursos teriam a duração de até quatro meses após a conclusão do curso normal com aulas teóricas e práticas e seus conteúdos eram: higiene rural, sociologia rural, educação rural e atividades rurais. Tudo isso para deixar o homem do campo mais "agradável" e menos "agressivo" ao homem civilizado (BEZERRA NETO, 2003).

Verifica-se que seriam destinados às populações do campo processos educativos que promovessem especialmente o desenvolvimento econômico do país, relacionados ao movimento do modo de produção e a modernização da agricultura que o caracteriza. Associados a essa promoção estavam também os ideais de homem que atendessem às exigências do referido processo de modernização. Nesse sentido, vale ressaltar as implicações sobre o modo de vida do homem no meio rural. Com uma breve análise da literatura, algumas características desse homem são observadas no personagem do Jeca Tatu, de Monteiro Lobato, que o representava como sujeito atrasado e simplório. Tal personagem foi utilizado na campanha em favor do saneamento, além de educar e esclarecer a população sobre uma doença tropical que fazia milhões de brasileiros como vítimas: o amarelão. Jeca Tatu tinha algumas pequenas plantações que lhe garantia o seu próprio sustento, mas era reconhecido como sujeito bêbado e preguiçoso. Compreende-se a intenção de promover a mudança nesse personagem à medida que ele passava, nas histórias, a não mais exagerar na bebida, a aumentar seu ritmo de trabalho, a andar calçado e ter outras atitudes que fizeram a fazenda prosperar e Jeca Tatu, ao longo da narrativa, se tornar muito respeitado.

Desse modo, pode-se observar que a Educação Rural oferecida no século XX tinha como parâmetro os processos educativos aplicados nas cidades, especialmente por conta do modo de produção capitalista. As políticas retratavam um trabalho embasado em projetos e campanhas firmadas no desejo de manter os sujeitos no meio rural sem pensar nas condições se eram viáveis e possíveis. Nesse contexto, compreende-se a criação e disseminação das escolas técnicas, pelas quais, de certo modo, o Estado consolidou suas determinações através da reforma educacional de 1942, com as Leis Orgânicas de Ensino implementadas por Gustavo Capanema. Tais reformas estariam associadas aos interesses dos empresários que viam no Estado a força para manter o capitalismo e, com o apoio da educação, formar a força do trabalho.

Assim, as escolas técnicas vão ser as escolas dos filhos dos outros, ou melhor, a única via de ascensão permitida ao operário. Que essa via é falsa e se revela um beco sem saída, está implícito na especificidade dessa escola. Sendo de nível médio ela não habilita seus egressos a cursarem escolas de nível superior. Criou-se a dualidade do sistema educacional que, além de reproduzir a força de trabalho para o processo produtivo, garante a consolidação e reprodução de uma sociedade de classes [...] (FREITAG, 1980, p.53).

Nessa perspectiva, além da formação do homem que residia no meio rural para a participação social pelo trabalho, almejava pelo processo educativo, a preparação técnica para a produção agrícola moderna. Esse caráter técnico irá se intensificar nos anos 1960 e 1970, momento em que houve muitos movimentos lutando pelo olhar mais focado no rural.

$\mathrm{O}$ mesmo enfoque instrumentalista e de ordenamento social veio a caracterizar a formação de técnicos para as atividades agropecuárias. Em meados da década de 1960, por ocasião da implantação do modelo Escola-Fazenda no ensino técnico agropecuário, os currículos oficiais 
foram elaborados com enfoque tecnicista para atender ao processo de industrialização em curso (BRASIL, 2007, p.11).

Nesse sentido, a educação no meio rural passou a ser dedicada à produção de alimentos, conteúdo que seria ensinado nas escolas técnicas ou agrícolas. Esse fator, no entanto, intensificou a saída do sujeito para o meio urbano, uma vez que diminuiu a oferta de trabalho no campo.

O avanço da tecnificação na agricultura é tão forte, que os trabalhos rurais são cada vez mais individualizados e menos familiares e a quantidade de produção são enormes. Tudo pode ser feito por um administrador, mesmo sem residir no campo. Os outros membros da família ficam livres para desenvolver as pluriatividades que não são rurais (DEL GROSSI, 1996, p.51).

Perante o processo de modernização agrícola, e a aplicação de processos técnicos disseminados pela educação no meio rural, ocorre um aumento do deslocamento dos sujeitos para as áreas urbanas, que caracterizou o Brasil do século $\mathrm{XX}$, e que pode ser identificado em vários estados, inclusive no Paraná. Segundo Tonete (2008), a modernização agrícola e a expansão territorial agrícola no Paraná foram as duas principais causas desse movimento migratório, pois ocorreu a diminuição da necessidade de mão-deobra no meio rural.

No Brasil, entre 1960 e 1980, ocorreu o maior número de migração "aproximadamente 13 milhões de pessoas abandonaram o campo e rumaram em direção aos centros urbanos. Isso equivale a 33\% da população rural" (TONETE, 2008, p.9). Segundo a autora (p. 5, grifo nosso), "O Exxodo Rural paranaense apresentou nos últimos 30 anos uma média superior ao nacional, o que evidencia uma política de incentivo à agroindústria, à monocultura de exportação e ao latifúndio rural e urbano." Esse fato ocorreu, principalmente, pela influência dos movimentos populacionais denominados de "movimentos pendulares" que influenciam muito na cultura e na economia, ou seja, na sociedade como um todo.

Nesse ponto, há uma contradição inerente ao modo de produção capitalista, uma vez que, ao mesmo tempo em que se esperava que a educação preparasse o sujeito do campo para o trabalho, as exigências da modernização agrícola e a consequente diminuição da oferta de emprego impulsionam a vinda desse sujeito para a cidade. A educação rural passa a ser compreendida como elemento essencial para "fixação" do homem no campo.

Na década de 60, a fim de atender aos interesses da elite brasileira, então preocupada com o crescimento do número de favelados nas periferias dos grandes centros urbanos, a educação rural foi adotada pelo Estado como estratégia de contenção do fluxo migratório do campo para a cidade. A Lei de Diretrizes e Bases da Educação Nacional de 1961, em seu art. 105, estabeleceu que 'os poderes públicos instituirão e ampararão serviços e entidades que mantenham na zona rural escolas capazes de favorecer a adaptação do homem ao meio e o estímulo de vocações profissionais'. (BRASIL, 2007, p. 11)

Nessa perspectiva, a educação é reconhecida, especialmente pela elite brasileira, como estratégia para, em um primeiro momento, modernizar a agricultura e, ao mesmo tempo, conter o fluxo migratório. A esse respeito Cavalcante $(2009$, p.2) afirma que entre algumas intervenções socioeducacionais para os adultos e adaptações para os menores, 
"sutilmente" delineava-se um perfil de estudante "possível" no rural, tentava-se instruir aquele que vivia no campo com o formato totalmente rural para ali permanecer e produzir. No mesmo sentido, Bareiro (2007) afirma que foi particularmente na década de 1970 que as propostas curriculares buscavam adaptar o sistema de trabalho dos agricultores familiares ao sistema dos grandes latifundiários sempre baseados numa produção de larga escala.

Agricultores abandonavam o campo, pela falta de uma política agrícola de valorização de seus produtos e por não terem as condições mínimas de adotar ou de enfrentar as novas tecnologias, ou as novas máquinas de preparar a terra, semear, colher, tirar o leite, aplicadas à agricultura e à pecuária e acabavam por engrossar a periferia das grandes cidades brasileiras. (BAREIRO, 2007, p. 21)

Interessa afirmar ainda que, a movimentação dos sujeitos do campo para a cidade apresentou dinâmica maior até a década de 1990, como destaca Del Grossi; Graziano da Silva; Campanhola (2001) na tabela abaixo.

Tabela 1. Evolução da população do Brasil ${ }^{a}$ no período 1981/1999.

\begin{tabular}{|c|c|c|c|c|c|c|c|c|c|c|}
\hline & \multicolumn{4}{|c|}{ População (milhão de pessoas) } & \multicolumn{6}{|c|}{ Taxa crescimento ( $\%$ ao ano) } \\
\hline & 1981 & 1992 & 1996 & 1999 & 1981 & & 199 & & 199 & $6 / 99$ \\
\hline URBANO & 85,2 & 113,4 & 122,4 & 127,8 & 2.6 & **** & 1.7 & ***** & 1.4 & **** \\
\hline Ocupados $^{\mathrm{b}}$ & 31,7 & 46,5 & 50,4 & 52,8 & 3,6 & $* * *$ & 1,8 & **** & 1,5 & **** \\
\hline Agricola & 2,6 & 3,7 & 3,4 & 3,4 & 3,3 & $* * *$ & -1.6 & **** & $-0,2$ & \\
\hline Năo-agricola & 29,1 & 42,9 & 47,0 & 49,3 & 3,6 & $* * *$ & 2,0 & **** & 1,6 & $* * *$ \\
\hline RURAL & 34,5 & 32,0 & 31,7 & & $-0,7$ & $* * *$ & 0,2 & $* * *$ & 1,1 & *** \\
\hline Ocupados & 13,8 & 14,7 & 139 & 14,9 & 0,6 & 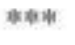 & $-0,2$ & ***** & 2,1 & $* *$ \\
\hline Agricola & 10.7 & 11,2 & 9,9 & 10,2 & 0,4 & 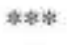 & $-1,7$ & **** & 0,4 & \\
\hline Não-agricola & 3,1 & 3.5 & 4.0 & 4,6 & 1,2 & 水: & 3,7 & $* * *$ & 6,1 & *** \\
\hline Total & 119,7 & 145,4 & 154,0 & 160,3 & 1,8 & atका & 1,4 & siniti & 1,3 & 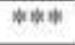 \\
\hline
\end{tabular}

Fonte: Tabulações especiais das PNADs de 1981 e de 1992 a 1999. Projeto Rurbano, novembro 2000.

NOTAS: a) não inclui as áreas da região Norte, exceto estado de Tocantins.

b) PEA restrita, que exclui os não-remunerados que trabalham menos de 15 horas na semana e os que se dedicam exclusivamente ao autoconsumo.

Pelos dados apresentados, pode-se identificar a diminuição do êxodo e um aumento da população no campo, mesmo com o emprego agrícola em baixa, contudo, considera-se que o movimento das populações não deixa de existir, porém, ocorre em menor quantidade. Esses sujeitos passaram também a trabalhar em outras atividades que não eram agrícolas.

Diante desse quadro aqui rapidamente traçado importa ressaltar o posicionamento daqueles que representam especificamente os grupos populacionais do campo, especialmente em relação aos processos educativos que demandam e impulsionam a Educação do Campo. Nesse sentido, Cavalcanti (2009) afirma que foi na metade do século XX que iniciou os movimentos de educação popular para contrapor o que estava instituído como política de educação para todos. A educação popular visava transformar pela educação e repensar a escola para os trabalhadores. Ela atingia as crianças, jovens e adultos tanto no campo quanto na cidade. Ainda segundo a autora, entre os anos 1950 e 1960, o meio rural começa a mostrar suas forças para a sociedade brasileira. A prática pedagógica dos quintais ao redor das escolas escrevia um novo referencial para a história da educação 
do meio rural: "A educação popular, entre a fé cristã de vida e de luta, inegavelmente trouxe para o contexto de mobilização social nos rurais do país, o potencial da educação de militância, inconformidade e rebeldia política" (CAVALCANTI, 2009, p.4).

Apesar dos esforços, somente na década de 1990 é que a Educação do Campo recebe mais força de lutas com a participação do Movimento dos Trabalhadores Sem Terra em conjunto com a Organização das Nações Unidas, a Universidade de Brasília e a Confederação Nacional dos Bispos do Brasil que pressionaram o Estado a dar prioridades para esse setor (CAVALCANTI, 2009).

Concomitantemente, destacam-se a intensificação das lutas camponesas afirmando ser sempre uma constante na história do Brasil, em especial no tratamento com a reforma agrária. Nota-se que as iniciativas dos governos não permitiram a consolidação do processo de democratização da terra no Brasil. Verifica-se, deste modo, outra questão fundamental para a compreensão do contexto histórico da Educação do Campo, pois, desde a década de 1930 se pensava numa educação tecnicamente para produzir no campo. Há vários movimentos sociais que lutam pela posse e uso da terra, muitos são diferentes quanto à organização, objetivos, mas todos lutam pela terra para continuar produzindo nelas como é o caso do MST.

É importante destacar que as lutas pela reforma agrária e as experiências vividas nas escolas de acampamentos e assentamentos do MST marcam esse processo histórico de luta por uma educação para o campo, portanto, a partir da segunda metade do século XX e, especialmente, nas décadas finais houve o direcionamento de uma atenção especial para a Educação do Campo enquanto possibilidade de emancipação humana e representação dos interesses dos grupos sociais e dos sujeitos do campo. Embora fosse inicial ainda esse processo de construção, contou com o apoio de universidades, movimentos sociais do campo e o Estado.

\section{Educação do campo e a autonomia em relação à permanência no campo}

Do que foi apresentado até o momento, uma questão merece ser destacada para fechar a discussão, relaciona-se a uma possível função da escola frente ao processo do Exxodo Rural. Observa-se que a Educação do Campo é abordada diferentemente da educação da cidade, pois se destina a outra população, possui diferentes metodologias e recursos, no entanto, seu papel é fundamental no processo de formação do indivíduo independente do lugar onde ele mora. Considera-se que a educação necessita ter um caráter emancipatório que proporcione o conhecimento e a opção de escolha por parte de quem a recebe.

Entretanto, para alcançar os objetivos educacionais, os professores devem compreender o que é educação e qual sua função social. É fundamental compreender a educação como um processo de apropriação e transformação da cultura. Segundo Bezerra Neto (2003, p.211), não é função da escola "fixar" as pessoas no campo, sendo que isso depende das medidas econômicas. De outra forma, não é função da escola retirar essas pessoas de lá. Ela pode mostrar por meio de um processo educativo a possibilidade de decisões autônomas dos sujeitos em relação à produção de suas vidas, formas de trabalho e locais de residência.

Em relação à função da escola ao longo da história, identifica-se que a preocupação do Estado pelo modelo tradicional deveria ser contra o analfabetismo para que todos pudessem ter contato com a "luz" do conhecimento. Nesse sentido, era necessário preparar a sociedade que estava por vir, baseada no modo de produção capitalista. Verifica-se, como 
discutido no tópico inicial, a diferenciação entre a cidade e o sertão, este possui um cenário diverso como se fosse isolado do mundo civilizado. Naquele momento, o que faltava era uma escola que soubesse preparar as pessoas para trabalhar com a terra e os animais e assim, possibilitar condições necessárias para que as pessoas continuassem vivendo no campo.

Observa-se que os objetivos da educação esbarram nos problemas especulativos e nas realidades sociais diversas para garantir com plenitude a sua eficiência. Sendo assim, o papel da escola na cidade se direciona prioritariamente à ação educativa, já no meio rural a escola muitas vezes é compreendida como a única instituição que procura agrupar diferentes tarefas para além da formação exclusivamente pedagógica.

Ao mesmo tempo, a suposição de que o conhecimento "universal", produzido pelo mundo dito civilizado deveria ser estendido - ou imposto - a todos, de acordo com a "capacidade" de cada um, serviu para escamotear o direito a uma educação contextualizada, promotora do acesso à cidadania e aos bens econômicos e sociais, que respeitasse os modos de viver, pensar e produzir dos diferentes povos do campo. Ao invés disso, se ofereceu, a uma pequena parcela da população rural, uma educação instrumental, reduzida ao atendimento de necessidades educacionais elementares e ao treinamento de mão-de-obra (BRASIL, 2007, p. 10).

Em meados do século XX, com a influência da escola nova e os fundamentos da psicologia aplicada à educação, ocorre uma aproximação da educação com a realidade dos alunos, inclusive do campo. Esta relação pode ser observada com a análise do filme Narradores de Javé, no qual existe uma cidade pequena prestes a desaparecer, no entanto, conta com a ajuda de seus moradores para continuar viva e não perder a sua história com a chegada do progresso e do avanço tecnológico. Nesse contexto, o filme aborda diversos temas, tais como: a formação cultural do povo, heranças históricas, crenças, valores, oposição entre história, memória, verdade e invenção, importância da oralidade na construção cientifica, dimensão da escrita e da fala, confronto entre as tradições e o progresso do vilarejo.

Conforme afirma Sousa (1944) a educação rural prejudica o campo, pois os jovens querem aprender os conhecimentos e deixam de trabalhar na terra e "enchem" as cidades. Nesse sentido, surgem decretos para se criar escolas em locais que se tenha produção rural e colocar os professores primários para conhecer a necessidades de cada lugar. Tudo isso para se ter uma formação baseada nos labores da terra e que não se interessem pelos prazeres da cidade. De acordo com Cruz (1944), há o interesse de um nível médio de cultura em grande massa, o que quer dizer que a grande parte dessas pessoas é do meio rural, mas não se trata de ensinar a ler e escrever apenas e sim, ajudar a produzir mais, possibilitar melhores condições de produção do seu trabalho, além de mantê-lo no campo.

Neste sentido, Viana (1944) frisa a questão dos conhecimentos que as crianças têm antes de entrar na escola que deve ser considerado de suma importância, além de serem aproveitadas dentro das escolas, suas experiências devem ser trabalhadas para se conseguir atingir os objetivos. Destaca ainda algumas sugestões para alcançar os objetivos gerais da educação como orientar a formação mental e moral do indivíduo, promover o alargamento das experiências infantis e com interesses dentro de um programa educativo.

No Brasil, houve tentativas de oferecer uma educação que contemplasse as necessidades ditadas por um sistema capitalista. No entanto, os alunos que hoje estão nas escolas apresentam problemas de indisciplina, defasagem de conteúdo, mas a situação se 
agrava quando estes alunos, após uma formação acadêmica, retornam à escola como docente trazendo consigo todas as dificuldades e vícios. Apesar da boa vontade de atuar apresenta um perfil de professor sem domínio de conteúdo e de turma e com pouca didática. Outro fator que contribui para isso é o fato do professor não ter conhecimento do Projeto Político Pedagógico, dessa forma, há uma dificuldade maior em realizar seu plano de trabalho docente compatível com o que se exige para aquele contexto.

Neste sentido, Adorno (1995) apresenta um diálogo entre ele e Becker sobre a educação e a sua função ou para onde ela deve conduzir:

Becker: Eu diria que atualmente a educação tem muito mais a declarar a cerca do comportamento do mundo do que intermediar para nós alguns modelos ideias preestabelecidos.

Adorno: Em relação a esta questão, gostaria apenas de atentar a um momento específico no conceito de modelo ideal, o da heteronomia, o momento autoritário, o que é imposto a partir do exterior. Nele existe algo de usurpatório. É de se perguntar de onde alguém se considera no direito de decidir a respeito da orientação da educação dos outros. (ADORNO, 1995, p. 141, grifo do autor)

Nessa perspectiva, Becker diz que hoje a educação precisa apontar o porquê do atual comportamento mundial ao invés de intermediar modelos já existentes. Adorno considera gravíssimo o fato de alguém se ver no direito de pensar uma educação para o outro. Nesse sentido, entraria em contradição a ideia de um ser autônomo e amancipado. Na sua concepção, a educação não é uma modelagem de pessoas, mas a produção de uma consciência verdadeira. É como se a ideia fosse política, ou seja, é necessário saber pensar por si só e não receber o pensamento pronto e elaborado por outras pessoas.

Porém, a resposta de Becker, nesse mesmo texto, atenta para o conceito de homem emancipado "é preciso tomar cuidado para não convertê-lo em orientador" (ADORNO, 1995, p.142). A juventude, por exemplo, na opinião de muitos professores desejaria modelos ideais ao invés de consciência crítica. Por isso, Adorno aponta que a ideia de emancipação "precisa ser inserida no pensamento e também na prática educacional (ADORNO, 1995, p.143). Observa-se que a ideologia dominante exerce uma pressão enorme sobre os sujeitos. Emancipar, desse modo, significa ter consciência e racionalidade, um movimento dialético. A educação seria ideológica se ignorasse isso e não preparasse o homem para a adaptação e orientação no seu meio.

Para ambos, Adorno e Becker, é impossível a orientação sem uma adaptação. É necessária a atenção para não perder a individualidade e nem no conformismo, ao mesmo passo que não se pode ignorar o indivíduo, também não se pode considerá-lo como supremo. Historicamente, a escola e a família fazem o papel de fortalecer mais a resistência do que a adaptação. Na infância, estaria o começo de tudo, mas as crianças estariam passando por esta fase com um empobrecimento de imagens, da linguagem e da expressão. São milhões de crianças que entram no processo educacional sem saber o porquê de estar ali e sem a oportunidade de compreender que a educação é o preparo para superar a alienação. Já na adolescência há uma rejeição de tudo o que não é diferenciado, isso ocorre porque não é estimulada a experiência ou a aptidão dos alunos, a qual permite a conscientização do que é importante para o momento, pois sem ela não se chega à reflexão. Um exercício sobre o pensar se faz necessário, indubitavelmente, em todos os níveis de educação (ADORNO, 1995).

No entanto, a sociedade não exige as propriedades específicas individuais reapresentando novas formas de comportamento. Sendo assim, surge um movimento em 
torno da colaboratividade que contribui com o enfraquecimento da formação do eu. Há certo paradoxo, pois a educação necessita dos indivíduos para não ser opressiva e, ao mesmo tempo em que os tem, transmite a sua ideologia. Um caminho possível seria colocar uma concessão no lugar da adaptação e trabalhar com a consciência para lutar pela resistência. Uma educação que invista na ruptura entre a teoria e a prática consciente do que está fazendo.

Adorno (1995) reforça que a emancipação é uma exigência na democracia e Becker concorda afirmando que não somos educados para a mesma. Contudo, é importante ter clareza do conceito sobre o talento, pois ele ajuda na emancipação "Evidentemente a aptidão para se orientar no mundo é impensável sem adaptações" (ADORNO, 1995, p. 144). O talento não se encontra configurado nas pessoas, mas sim, no seu desenvolvimento através da motivação. Desse modo, outro ponto discutido é o da autonomia oposta à autoridade. $\mathrm{O}$ autor explica que a autoridade é algo psicossocial sem ser propriamente a própria realidade social. Ele faz referência a uma pesquisa, a qual demonstrou que crianças que viviam compartilhando do mesmo discurso demoravam mais para perceber que a autoridade que eles viam na figura do pai não corresponde ao ideal para elas, enquanto que aquelas crianças mais comportadas conquistaram a sua autonomia antes.

Ao considerar o contexto escolar é necessário pensar nos professores, no entanto estes não podem ser tão autoritários de modo que provoquem o afastamento dos alunos. $\mathrm{O}$ trabalho em prol da educação para a emancipação é para a devida preparação do fortalecimento do "eu" e para que sempre esteja preparado para novas experiências numa sociedade heterônoma. Adorno e Becker sugerem que se faça uma educação reformada, fora dos padrões conhecidos, com ofertas de disciplinas diversificadas. Nesse sentido, o aluno participa da escolha do programa de estudos e da seleção das disciplinas. Isso lhe renderia mais motivação e também estaria mais participativo nas decisões dos currículos escolares. Nessa perspectiva, a concretização da emancipação ocorre pela resistência e pela contradição do que está ou é imposto. Porém, até o homem emancipado pode estar em perigo porque vive em uma sociedade não emancipada e pode enfrentar muitas resistências e crenças de que isso é utópico. No entanto, é possível fazer uma educação emancipadora que contribua na formação pessoal possibilitando pensar e agir diferentemente daquilo que é imposto pela sociedade e evitando o comodismo (ADORNO, 1995).

Ao longo da análise observa-se que tudo começa na infância e tem maior poder na adolescência, período de transformações pessoais. Se as crianças se educam num meio doentio, será impossível torná-las sadias pelo processo natural da educação. Por outro lado, o que predomina é a visão do aluno que já chega à escola como um terreno já explorado e que traz potencialidades que nem sempre são positivas. Ele é fruto de uma cultura dominante. Sendo assim, é de suma importância acreditar que, se houver uma educação que intervenha diretamente com outra visão, ela conseguirá formar uma pessoa madura, autônoma e, talvez, emancipada. Mas isso não se constrói no vazio, depende das decisões tomadas na e pela sociedade. Logo, teremos seres críticos frente às ilusões ideológicas da cultura como um todo.

A Educação do Campo deseja uma educação para/no o campo, considerando a vida que se realiza diariamente juntamente com a forma de lidar com o ambiente e dele retirar o seu sustento. Existe uma luta desse reconhecimento para transformar isso em conteúdo a ser trabalhado na escola com a perspectiva de mudar as relações de poder que existem. A função da escola não é a de conter o fluxo, mas de emancipar, e, pela mediação do conhecimento permitir escolhas autônomas e posicionamentos políticos coerentes.

Nesse sentido, é importante destacar as lutas dos movimentos sociais, pois geralmente visam uma escola melhor para seus filhos, da qual eles não puderam desfrutar. 
No entanto, a população do campo precisa estar ciente da existência de seus direitos de ter uma educação que forma sujeitos que dialogam com os poderes públicos. É necessário reconhecer o campo como uma luta social, pois assim, objetiva chegar à renovação da escola. Ao reconhecer que o campo já nos ensina bastante, entretanto, ainda é necessária uma educação que faça o homem do campo ter consciência de si para escolher sozinho em qual lugar vai morar.

Segundo o que foi exposto, denota-se que a educação rural brasileira e as pessoas que dela necessitavam eram deixadas em segundo plano, embora houvesse por alguns momentos manifestações de interesse em ofertar um serviço de qualidade também para esse campo. Uma vergonha para a nossa história, pois apresentou falhas com a educação, da qual muito se tem falado em promover o desenvolvimento do país.

\section{Considerações finais}

No decorrer dos anos houve várias transformações e modernizações provocando uma mudança do Estado em Estado Mínimo, ou seja, objetiva desenvolver a economia, reformar a educação e aumentar o ambiente privado. No contexto do neoliberalismo surge três objetivos para a educação. Primeiro ela prepara para o trabalho e a pesquisa acadêmica fica ligada as necessidades do mercado. O segundo é tornar a escola um meio de transmissão doutrinária. E o terceiro é fazer da escola um mercado para os produtos da indústria cultural e da informática.

Desse modo, considera-se que alguns dos condicionantes que provocaram o aumento do êxodo do homem do campo vindo a povoar os centros urbanos, mesmo que para trabalhar em serviços pesados e ganhando pouco, foram o crescimento econômico do país juntamente com a modernização e exportação de produtos agrícolas. Ou seja, quem não conseguia acompanhar essa tecnologia dominante acabava tendo suas produções limitadas. Sendo assim, esses sujeitos arrendam as terras para conseguir o mínimo de sustento para sua família, ou vão à busca de trabalho nas cidades, mesmo que seja para trabalharem com serviços domésticos, motoristas ou trabalhos braçais.

Verifica-se que a Educação do Campo no Brasil é resultado de um processo histórico, social, econômico, político e cultural vivenciado no país. As escolas rurais foram sempre tratadas com projetos, políticas compensatórias e campanhas emergenciais sem muita continuidade. Identifica-se uma ausência de políticas públicas e diretrizes políticas particulares que viabilizassem uma escola com qualidade para todos os níveis de ensino no meio rural.

Observa-se que ao longo do século XX, mais precisamente de 1930 até por volta de 1990, houve uma intensificação do movimento migratório da população do campo para as cidades. Nesse momento histórico, a educação sofreu forte influência do ruralismo pedagógico na elaboração de projetos educacionais para as pessoas que moravam no campo não saíssem de lá. Nesse sentido, o Êxodo Rural deve ser entendido articulado às demandas do modo de produção, caracteristicamente capitalista, a partir da modernização da agricultura.

Destaca-se que uma possível função da escola frente ao processo do Exxodo Rural é o fato dela ser considerada diferente da educação urbana, pois o seu papel é fundamental no processo de formação do indivíduo no contexto rural. Sendo assim, a educação, necessita ter um caráter emancipatório que proporcione o conhecimento as populações da área rural possibilitando a liberdade de escolha do lugar aonde desejam morar, das roupas que vão vestir, dos alimentos que vão consumir, enfim, ter autonomia nas suas escolhas. 
Observa-se que, durante muito tempo, a educação foi objeto de interesse por parte de governantes para trilhar o caminho da população do campo se utilizando, muitas das vezes, de modelos urbanos que não davam certo no campo. A finalidade da escola era só uma: fixação do homem no campo ensinando técnicas e métodos para obter uma produtividade maior e promover o desenvolvimento do país. Para isso, as escolas técnicas foram criadas, mas não eram todos os alunos que tinham acesso e em muitos casos essas escolas estavam localizadas fora do meio rural. O Êxodo Rural só reforça a ideia de existir a discriminação notada pelas políticas públicas no campo da educação. No entanto, considera-se que a educação não deve ser algo utilizado para "fixar" essas pessoas no campo, nem mantê-las no meio urbano. Seu papel é, através de uma educação emancipadora, proporcionar ao indivíduo um posicionamento político coerente e a autonomia para decidir o que deseja fazer.

Considera-se ainda um novo perfil do agricultor com características diferentes de décadas atrás. Faz-se necessária uma organização da agricultura e dos seus membros envolvidos para atender a suas várias necessidades de forma singular. Hoje, em muitos casos, a agricultura se desenvolve voltada para a sustentabilidade conforme destaca Grossi (1996). No mesmo sentido, Tonete (2008) afirma que essa mobilidade populacional continua ocorrendo, com novos interesses e em novas direções, o certo é que a população sempre se desloca em busca de melhores oportunidades, transformando as relações socioespaciais.

Nota-se que a educação recebe uma conotação diferente em vários momentos da história. Ora ela é responsabilizada pela pouca produção dos agricultores e pelo processo do Exxodo Rural, ora como fundamental para ajudar a desenvolver integralmente a comunidade rural nas concepções sociais, econômicas, políticas e culturais de todos os envolvidos no processo educativo. Dessa forma, considera-se que o presente trabalho pode ajudar a rever alguns conceitos que se tem sobre a educação e a sua função pensada para as populações do campo em nossa sociedade capitalista.

\section{Referências}

ADORNO, Theodor Ludwig Wiesengrund. Educação e emancipação. In: ADORNO, Theodor Ludwig Wiesengrund. Educação e emancipação. Rio de Janeiro: Paz e Terra, 1995. p.169 - 185.

Educação para quê? In: ADORNO, Theodor Ludwig Wiesengrund. Educação $e$ emancipação. Rio de Janeiro: Paz e Terra, 1995. p.139 - 155.

APLLE, Michael Whitman. Ideologia e Currículo. São Paulo: Brasiliense, 1979.

BAREIRO, Edson. Políticas educacionais e escolas rurais no Paraná - 1930 - 2005. Maringá: UEM, 2007.

BEZERRA NETO, Luiz. Avanços e retrocessos na educação rural no Brasil. Campinas. 2003. Tese - UNICAMP.

BRASIL. Ministério da Educação. Secretaria de Educação Continuada, Alfabetização e Diversidade. Educação do Campo: diferenças mudando paradigmas. Brasília: Secad/MEC, 2007. Cadernos Secad. V. 2. 
CALDART, Roseli Salete. Educação do campo. In: CALDART, Roseli Salete (org.). Dicionário da Educação do Campo. Rio de Janeiro, São Paulo: Escola Politécnica de Saúde Joaquim Venâncio, Expressão Popular, 2012.

CAVALCANTE, Ludmila Oliveira Holanda. Das políticas ao cotidiano: entraves e possibilidades para a Educação do Campo alcançar as escolas no rural. UEFS. 2009. In: $<$ http://www.anped.org.br/reunioes/32ra/arquivos/trabalhos/GT03-5106--Res.pdf $>$. Acesso em 19-10-2010.

CRUZ, Noemia Saraiva de Matos. A educação rural nas zonas rurais comuns. In: ASSOCIAÇÃO BRASILEIRA DE EDUCAÇÃO. Anais do VIII Congresso Brasileiro de Educação. Rio de Janeiro: Serviço Gráfico da ABE, 1944.

DEL GROSSI, Mauro Eduardo; GRAZIANO DA SILVA, José; CAMPANHOLA, Clayton. O fim do Êxodo Rural? In: Espaço e Geografia (UnB), Brasília - DF, v. 4, n. 1, p. 01-12, 2001.

DEL GROSSI, Mauro Eduardo. Transformações no meio rural paranaense. In: XXXIV Congresso Brasileiro de Economia e Sociologia Rural, 1996, Aracaju - SE. Anais do XXXIV Congresso. Brasília - DF : SOBER - Sociedade Brasileira de Economia e Sociologia Rural, 1996. v. 1.p. 51-70.

FREITAG, Barbara. Escola, estado e sociedade. São Paulo: Moraes, 1980.

GODOY, Arilda. Introdução à pesquisa qualitativa e suas possibilidades. In: Revista de Administração de Empresas. São Paulo: v.35, n.2, p. 57-63, abril 1995.

JECA Tatu. Direção Milton Amaral. PAM filmes: São Paulo, 1959. 1 filme (1h 35min). Son. Preto e branco, $35 \mathrm{~mm}$.

LOBATO, Monteiro. Jeca tatu. In. Mr. Slang e o Brasil e problema vital. São Paulo: Brasiliense, 1961. p 329-340.

NARRADORES de Javé. Direção Eliane Caffé. Dist. Rio Filmes, 2003. 1 filme (1h 40 min), son: color.

SOUSA, Moreira de. O professor primário das zonas rurais: formação, aperfeiçoamento, remuneração e assistência. In: ASSOCIAÇÃO BRASILEIRA DE EDUCAÇÃO. Anais do VIII Congresso Brasileiro de Educação. Rio de Janeiro: Serviço Gráfico da ABE, 1944.

TONETE, Maria de Lourdes Bassi Alves; LIMA. Maria das Graças. A Influência dos Movimentos Populacionais na Formação Econômica e Social do Município de Peabiru. 2008. (Desenvolvimento de material didático ou instrucional - artigo). Disponível em: $<$ http://www.diaadiaeducacao.pr.gov.br/portals/pde/arquivos/272-4.pdf $>$. Acesso em: $06 / 06 / 2011$.

VIANA, Dulcie Kanitz Vicente. Haverá diferença entre os objetivos gerais da educação ministrada nos dois tipos de escola rural e urbana. In: ASSOCIAÇÃO BRASILEIRA DE EDUCAÇÃO . Anais do VIII Congresso Brasileiro de Educação. Rio de Janeiro: Serviço Gráfico da ABE, 1944. 


\title{
Notas:
}

\begin{abstract}
${ }^{1}$ Mestranda em Educação pela Universidade Estadual do Centro Oeste - UNICENTRO. O presente trabalho foi realizado com o apoio da FUNDAÇÃO ARAUCÁRIA Fundação de Apoio à Educação, Pesquisa e Desenvolvimento Científico e Tecnológico do Paraná - Brasil. Email: denisesikora@gmail.com

${ }^{2}$ Refere-se à Educação do Campo, no texto, a educação destinada as pessoas residentes no meio rural que tem por objetivo relacionar seus conhecimentos com questões de trabalho, cultura e relações sociais.
\end{abstract}

(CALDART, 2012)

${ }^{3}$ Entende-se por Exxodo Rural o processo migratório do campo para a cidade.

${ }^{4}$ No decorrer do texto serão nomeados apenas de Movimentos. Em relação às ações educativas pode-se destacar, além do Movimento Nacional dos Trabalhadores Rurais Sem Terra (MST), as iniciativas da Comissão Pastoral da Terra (CPT), da Confederação Nacional dos Trabalhadores na Agricultura (Contag) e do Movimento Eclesial de Base (MEB). Podem ser incluídas ainda as Escolas Famílias Agrícolas (EFAs), as Casas Familiares Rurais (CFRs) e os Centros Familiares de Formação por Alternância (CEFAs).

${ }^{5}$ Ruralistas era o termo utilizado para designar os grandes proprietários de terras em defesa de seus interesses políticos e econômicos.

${ }^{6}$ Entende-se por Educação Rural os processos e práticas educativas destinadas para residentes no meio rural, considera a dualidade entre urbano e rural, sendo o rural característico de atrasado.

Recebido em

outubro-12

Aprovado em abril-13 